UDK $903.01 / .09$

Submitted: 15.02 .2018

LBC 63.4(2)

Accepted: 10.04.2018

\title{
RED PIGMENTS IN THE BRONZE AGE BURIALS IN THE NORTH CAUCASUS: COMPLEX ANALYSIS FOR IDENTIFICATION OF PYROPROCESSING OF IRON MINERALS ${ }^{1}$
}

\author{
Pavel I. Kalinin \\ Institute of Physical-Chemical and Biological Problems of Soil Science, Russian Academy of Sciences, \\ Pushchino, Russian Federation
}

Viktor A. Trifonov

Institute for the History of Material Culture, Russian Academy of Sciences, Saint Petersburg, Russian Federation

Natalya I. Shishlina

State Historical Museum, Moscow, Russian Federation

Andrey O. Alekseev

Institute of Physical-Chemical and Biological Problems of Soil Science, Russian Academy of Sciences, Pushchino, Russian Federation

\begin{abstract}
Ochre is a natural pigment of yellow or red color, mainly consisting of iron minerals. Along with determining the origin of mineral dyes, one of the main problems of studying natural pigments in archaeology is identifying the origin of the so-called "red" ochre, made on the basis of hematite. Hematite is a widespread $\stackrel{\infty}{\sim}$ mineral found everywhere. However, it can be obtained by pyroprocessing goethite, which is the main component $\curvearrowright$ of the "yellow" ochre. To test the hypothesis of the red ochre production through the pyroprocessing of iron 0 oxides, 3 samples of ochre from the burials of the Bronze Age in the Republic of Adygea and the Krasnodar area have been studied. To identify the traces of thermal treatment of the raw ochre, we've carried out complex \& analysis, including the X-ray diffractometry, element analysis, infrared spectroscopy and microstructure analysis. The traces of the pyroprocessing have been revealed in the ochre sample from the burial of the Early Bronze Age near the Kazanskaya settlement. The form and size of the hematite crystals in the burial of the Ladozhskaya $\therefore$ settlement indicate the unperformed heat treatment and the endogenous origin. The sample from the I. Novosvobodnaya village shows the traces of pyroprocessing, but the pigment's microstructure indicates the sedimentary origin of the iron minerals from which it is composed. It's been found that the color of pigments does not depend on the percentage of iron in the raw material sample. The presence and the ratio of hematite and goethite in the pigment, as well as the composition of other minerals in the final product are the most significant discoveries.

P.I. Kalinin has carried out the complex analysis of pigment properties, data interpretation, literature review and paper writing; V.A. Trifonov has determined the archaeological context, interpreted the data, edited paper and approved the final version; N.I. Shishlina has provided samples for analysis, interpreted the data, made fundamental editiond to the paper; A.O. Alekseev has interpreted the mineralogical analysis and made certain amendments. culture.

Key words: ochre, pigments, hematite, goethite, pyroprocessing, complex analysis, North Caucasus, Maykop

Citation. Kalinin P.I., Trifonov V.A., Shishlina N.I., Alekseev A.O. Red Pigments in the Bronze Age Burials in the North Caucasus: Complex Analysis for Identification of Pyroprocessing of Iron Minerals. Vestnik Volgogradskogo gosudarstvennogo universiteta. Seriya 4, Istoriya. Regionovedenie. Mezhdunarodnye otnosheniya [Science Journal of Volgograd State University. History. Area Studies. International Relations], 2018, vol. 23, no. 3, (2) pp. 82-91. (in Russian). DOI: https://doi.org/10.15688/jvolsu4.2018.3.7
\end{abstract}




\title{
КРАСНЫЕ ПИГМЕНТЫ В ПОГРЕБЕНИЯХ ЭПОХИ БРОНЗЫ НА СЕВЕРНОМ КАВКАЗЕ: МЕТОДИКА ИДЕНТИФИКАЦИИ ПРИЗНАКОВ ТЕРМИЧЕСКОЙ ОБРАБОТКИ МИНЕРАЛЬНОГО ЖЕЛЕЗОСОДЕРЖАЩЕГО СЫРЬЯ ${ }^{1}$
}

\author{
Павел Иванович Калинин \\ Институт физико-химических и биологических проблем почвоведения РАН, \\ г. Пущино, Российская Федерация
}

\section{Виктор Анатольевич Трифонов}

Институт истории материальной культуры РАН, г. Санкт-Петербург, Российская Федерация

\section{Наталья Ивановна Шишлина}

Государственный исторический музей, г. Москва, Российская Федерация

\section{Андрей Олегович Алексеев}

Институт физико-химических и биологических проблем почвоведения РАН, г. Пущино, Российская Федерация

Аннотация. Охра - это природный пигмент желтого или красного цвета, преимущественно состоящий из минералов железа. Наряду с определением источника происхождения минеральных красителей, одной из главных проблем изучения природных пигментов в археологии является вопрос происхождения так называемой красной охры, изготовленной на основе гематита. Для проверки гипотезы об изготовлении красной охры путем термической переработки железистых минералов исследовали 3 образца охр из погребений эпохи ранней бронзы, расположенных в Республике Адыгея и Краснодарском крае. Для идентификации признаков термической обработки охр был разработан комплексный анализ с применением рентгеновской дифрактометрии, элементного анализа, инфракрасной спектроскопии и анализа микроструктуры. В образце из погребения эпохи бронзы у ст-цы Казанская выявлены признаки термической обработки минерального пигмента. Форма и размер кристаллов гематита в погребении у ст-цы Ладожская указывают на отсутствие его термической обработки и эндогенное происхождение. В образце из ст-цы Новосвободная не обнаружено признаков обжига, а микроструктура пигмента указывает на осадочное происхождение минералов железа, из которых он состоит. Установлено, что цвет пигментов не зависит от процента содержания в них железа. Наиболее значимым является наличие и соотношение гематита и гетита в пигменте, а также состав примесей других минералов в конечном продукте. Вклад авторов: П.И. Калинин - разработка и проведение комплексного анализа свойств пигментов, интерпретация данных, обзор литературы, написание текста статьи; В.А. Трифонов - определение археологического контекста, интерпретация данных, написание статьи и внесение принципиальных изменений, одобрение окончательной версии; Н.И. Шишлина - предоставление образцов для анализа, интерпретация данных, внесение принципиальных изменений в текст статьи; А.О. Алексеев - интерпретация минералогического анализа, внесение принципиальных изменений в текст статьи.

Ключевые слова: охры, пигменты, гематит, гетит, обжиг, анализы, Северный Кавказ, майкопская культура.

Цитирование. Калинин П. И., Трифонов В. А., Шишлина Н. И., Алексеев А. О. Красные пигменты в погребениях эпохи бронзы на Северном Кавказе: методика идентификации признаков термической обработки минерального железосодержащего сырья // Вестник Волгоградского государственного университета. Серия 4, История. Регионоведение. Международные отношения. - 2018. - Т. 23, № 3. - С. 82-91. - DOI: https:// doi.org/10.15688/jvolsu4.2018.3.7 


\section{Введение}

Курганы и широкое использование в погребениях красной минеральной краски еще в конце XIX в. превратились в символы культур эпохи бронзы в южнорусских степях и на Северном Кавказе [9]. В ходе изучения состава красок красных оттенков было установлено, что чаще всего они представляют разновидности соединений на основе железа, и в археологии за ними закрепилось общее название «охра». Как правило, полагали, что «охры» являются не требующими какой-либо дополнительной обработки природными минералами, а их химический состав может прямо указывать на область происхождения [1].

Недавние исследования показали, что краски на основе окислов железа являются продуктом пиротехнической обработки сырья, содержащим гетит и гематит. При ограниченном количестве источников готовых природных пигментов красных оттенков массовый и регулярный спрос на красную охру, скорее всего, удовлетворялся за счет ее производства из доступных железистых минералов [4]. Химический и минеральный состав конечного продукта зависел как от состава исходного минерального сырья, так и от состава глиняного наполнителя для изготовления стандартизированных брусков краски, в которых она поступала на рынок обмена и к конечному потребителю.

Основная цель настоящего исследования состоит в дальнейшей разработке комплексной методики идентификации признаков термической переработки минерального железосодержащего сырья с использованием элементного анализа, рентгеновской дифрактометрии, инфракрасной спектроскопии и анализа микроструктуры пигмента [4, с. 38].

\section{Методы}

В природе существует множество горных пород, обогащенных окислами (гематит $\mathrm{Fe}_{2} \mathrm{O}_{3}$ ) и гидроокислами (гетит FeOOH) железа. Охра - это природный пигмент желтого или красного цвета, преимущественно состоящий из минералов железа. Наряду с определением источника происхождения минеральных красителей, одной из главных проблем изучения при- родных пигментов в археологии является вопрос происхождения так называемой красной охры, изготовленной на основе гематита $\left(\mathrm{Fe}_{2} \mathrm{O}_{3}\right)$. Гематит - широко распространенный минерал, который встречается повсеместно и нередко образует большие скопления и рудные залежи. Однако его можно получить еще одним известным с древних времен способом путем обжига гетита (FeOOH), который является основным компонентом «желтых» охр. Гетит неменее распространенный минерал, чем гематит. Встречается в виде продукта выветривания; образуется при нормальных температуре и давлении из других железосодержащих минералов (сидерита, магнетита, пирита и др.) либо как продукт осаждения в болотах и природных источниках.

Переход гетита в гематит идет в соответствии со следующей химической реакцией:

$$
\mathrm{FeOOH} \rightarrow \mathrm{Fe}_{2} \mathrm{O}_{3}+\mathrm{H}_{2} \mathrm{O}
$$

В почвоведении и археологии долгое время считалось, что буроокрашенный гетит может переходить в красноокрашенный гематит непосредственно после погребения с потерей конституционной воды при высоких температурах почвы [1, с. 163]. Однако с появлением методов мессбауэровской спектрографии, электронной микроскопии и рентгеновской дифрактометрии возможность таких переходов была отвергнута. Формирование гидрогематита возможно только через фазу ферригидрита. Ферригидрит $\left(\mathrm{Fe}_{2} \mathrm{O}_{3} \cdot 2 \mathrm{FeOOH} \cdot 2,6 \mathrm{H}_{2} \mathrm{O}\right)-$ эфемерный гидроксид, в почве он постепенно превращается в более стабильные формы: гетит или гематит в зависимости от условий. Подробная схема оксидогенеза железа была составлена Швертманном еще в 1989 г. с дополнениями; за последние два десятилетия исследований в ней представлено взаимное превращение минералов железа: гематита, гетита, ферригидрита, маггемита, лепидокрокита [11]. В частности, в почвенных исследованиях выявлено, что красная окраска почвенной массы появляется благодаря присутствию гематита и тесно коррелирует с его относительным содержанием в сумме минералов «гетит + гематит». Вместе с тем обнаружена невозможность непосредственного перехода этих минералов друг в друга в зоне гиперге- 
неза. Также невозможно формирование гематита в гипергенных температурных условиях непосредственно из железосодержащих растворов. Лабораторные исследования показывают, что прямая трансформация гетита в гематит требует температуры около $400{ }^{\circ} \mathrm{C}$, а обратный переход происходит в присутствии воды при температуре около $130{ }^{\circ} \mathrm{C}$, что в природных условиях практически невозможно. Универсальным механизмом для перехода одного оксида железа в другой в почвах является переход железа в раствор и образование из него нового соединения [2].

Определение признаков гематита, полученного путем обжига, до сих пор является нерешенной задачей, над которой работают многие исследователи. Гетит полностью разрушается и начинает переходить в гематит при температуре $340{ }^{\circ} \mathrm{C}$ [3]. Проведенные нами эксперименты по прокаливанию гетита до температуры $600,700,800$ и $900{ }^{\circ} \mathrm{C}$ показывают полную трансформацию гетита в гематит при $800{ }^{\circ} \mathrm{C}[4$, c. 39]. При этой же температуре образец приобретает ярко-красный цвет (5YR 5/6 по шкале Манселла). Однако химический состав и свойства природного и прокаленного гематита одинаковы, рентгеновские дифрактограммы также не выявляют отличий. Кроме того, решение задачи по установлению признаков термической обработки пигментов значительно усложняется их полиминеральным составом. Минералы, входящие в состав охр, могли попасть туда на любом этапе их изготовления, погребения или пробоотбора. Наличие в образце гематита или гидрогематита само по себе не является доказательством обжига, так как эти минералы широко распространены в осадочных породах, где они одновременно образуются в результате выветривания первичных минералов и выпадения из растворов [12]. К тому же эти минералы могли попасть в пигмент при его смешивании с почвой или глинистыми минералами. По этой же причине совместное обнаружение в охре гетита и гематита не служит доказательством отсутствия термической обработки образца, так как гетит является не менее распространенным минералом, чем гематит.

Поэтому сам по себе минеральный, а соответственно, и элементный анализ не может являться надежным доказательством наличия технологической обработки природного минерала. Для получения надежных доказательств термического воздействия необходимо применять комплексный подход с использованием рентгеновской дифрактометрии, элементного анализа, инфракрасной спектроскопии и анализа микроструктуры пигмента.

В данном исследовании определение химического состава образцов, учитывая малые навески, проводилось с использованием микроанализатора (ЭДС) сканирующего электронного микроскопа SEM TESCAN VEGA 3 LMU при ускоряющем высоком напряжении $30 \mathrm{keV}$, в режиме SE (Secondary Electron Image) и высокого вакуума (HV). Интегрированный в микроскоп ЭДС-энергодисперсионный спектрометр (Oxford Instruments) и программа AZtec использовались для получения количественных результатов элементного анализа образцов пигментов.

Минералогический состав валовых образцов охр изучен методом рентгеновской дифрактометрии на приборе D2 PHASER (Bruker), $\mathrm{CuK \alpha}$ излучение, дифрактограммы получены в интервале 5-65 $2 \Theta$ с шагом $0,02^{\circ}$ и временем набора 5 с на точке. Образцы приготовлены из спиртовой суспензии. Качественный и полуколичественный фазовый анализ выполнен с применением программы DIFRAC.EVA (BRUKER) с использованием базы данных ICDD PDF2 (Международный центр дифракционных данных - International Centre for Diffraction Data (ICDD)).

ИК-спектры образцов были получены на приборе ИК-Фурье спектрометр «Тhermo Scientific Nicolet 6700» в диапазоне 4000$400 \mathrm{~cm}^{-1}$ (техника $\mathrm{KBr}$ ). Препараты для съемки готовились путем измельчения 1 мг пробы и 199 мг $\mathrm{KBr}$ до состояния пудры и дальнейшего прессования твердых проб в таблетки.

Цвет пигментов определялся по цветовой шкале Манселла.

С помощью комплекса инструментальных методов изучены 3 образца пигментов (см. рис. 1):

1. Погребение эпохи бронзы у ст-цы Ладожская, раскопки Н.И. Веселовского, 1902 г. $[8$, c. $74-77]$.

2. Погребение эпохи бронзы у ст-цы Казанская, раскопки Н.И. Веселовского, 1901 г. $[7$, c. $66-80]$. 


\section{МЕЖДИСЦИПЛИНАРНЫЕ ИССЛЕДОВАНИЯ}

3. Образец «краски» с крыши дольмена, относящегося к позднему этапу развития майкопской культуры (новосвободненский вариант). Адыгея, ст-ца Новосвободная (бывшая Царская) - курган 1 (по нумерации Н.И. Веселовского) [6], раскопки ИИМК-ГИМ, 2014 год.

\section{Анализ}

\section{Химический состав}

Химический состав изученных образцов характеризуется наибольшим содержанием Fепо сравнению с другими элементами (см. табл. 1). Однако значительное содержание $\mathrm{Si}, \mathrm{Al}$ и $\mathrm{Ca}$ указывает на наличие в пигментах примесей, которые могли попасть туда как при приготовлении охры, так и в результате пробоотбора. Обращает на себя внимание наличие в образце № $3 \mathrm{Mn} \sim 3,12 \%$, который отсутствует в других пигментах. Не отмечается его присутствие и в известняке, из которого состоит плита с найденной на ней охрой.

Сравнение химического состава и цветовой гаммы изученных образцов (см. рис. 1) позволяет сделать вывод, что цвет пигментов не зависит от процента содержания в них железа. Наиболее значимым является минеральный состав охр.

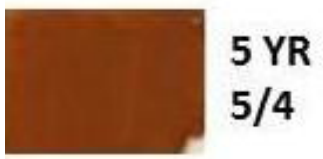

№1

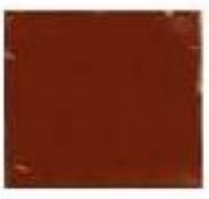

№2

С помощью сканирующего электронного микроскопа была изучена микроструктура образцов пигментов. В образце № 1 обнаружены характерные кристаллы гематита размером до 5 мкм, имеющие ромбоэдрическую кристаллическую структуру [10] (см. рис. 2). Наличие подобных крупных кристаллов правильной формы является признаком длительного процесса кристаллизации, проходившего в благоприятных условиях. Это подтверждает и минеральный состав, а именно совместное нахождение в нем гетита и гематита (см. табл. 2).

Кроме того, на инфракрасном спектре не отмечается смещение полосы гематита $540 \mathrm{~cm}^{-1}$, характерное для гематита, полученного при термической обработке. Все это указывает на отсутствие технологического процесса в изготовлении пигмента № 1. Однако происхождение таких форм кристаллов гематита в зоне гипергенеза или в виде тонкодисперсной примеси в осадочных породах в результате перекристаллизации из ферригидрита является маловероятным. Первоначальным источником гематита служит закисное железо $(\mathrm{Fe} 2+)$, которое под воздействием железобактерий (обычно Galionella, Leptothrix, Toxothrix), активных при значениях $\mathrm{pH}$, близких к 6-7, и температурах от 4 до $27^{\circ} \mathrm{C}$, преобразуется в ферригидрит $\left(2,5 \mathrm{Fe}_{2} \mathrm{O}_{3} \cdot 4,5 \mathrm{H}_{2} \mathrm{O}\right)$.

\section{2,5 YR $3 / 8$}

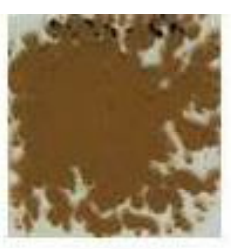

№3
25 YR $6 / 2$

Рис. 1. Цвет изученных образцов пигментов (по шкале Манселла)

Fig. 1. The color of the studied samples of pigments (based on the Munsell scale)

Таблица 1

\section{Химический состав изученных образцов пигментов}

\begin{tabular}{|l|r|r|r|}
\hline Образец & \multicolumn{1}{c|}{ № 1 } & \multicolumn{1}{c|}{ № 2 } & \multicolumn{1}{c|}{ № 3 } \\
\hline Fe (\%) & 26,16 & 44,20 & 33,52 \\
\hline Mn (\%) & - & - & 3,12 \\
\hline S (\%) & 0,69 & 2,60 & - \\
\hline Si(\%) & 13,49 & 6,10 & 10,07 \\
\hline Al (\%) & 8,0 & 2,50 & 3,17 \\
\hline Ca (\%) & 2,10 & 3,50 & 1,72 \\
\hline P (\%) & 1,64 & 1,00 & 0,59 \\
\hline K (\%) & 1,34 & 0,60 & 1,12 \\
\hline Ti (\%) & 0,39 & 0,30 & - \\
\hline Mg (\%) & 0,41 & 0,20 & 0,34 \\
\hline
\end{tabular}



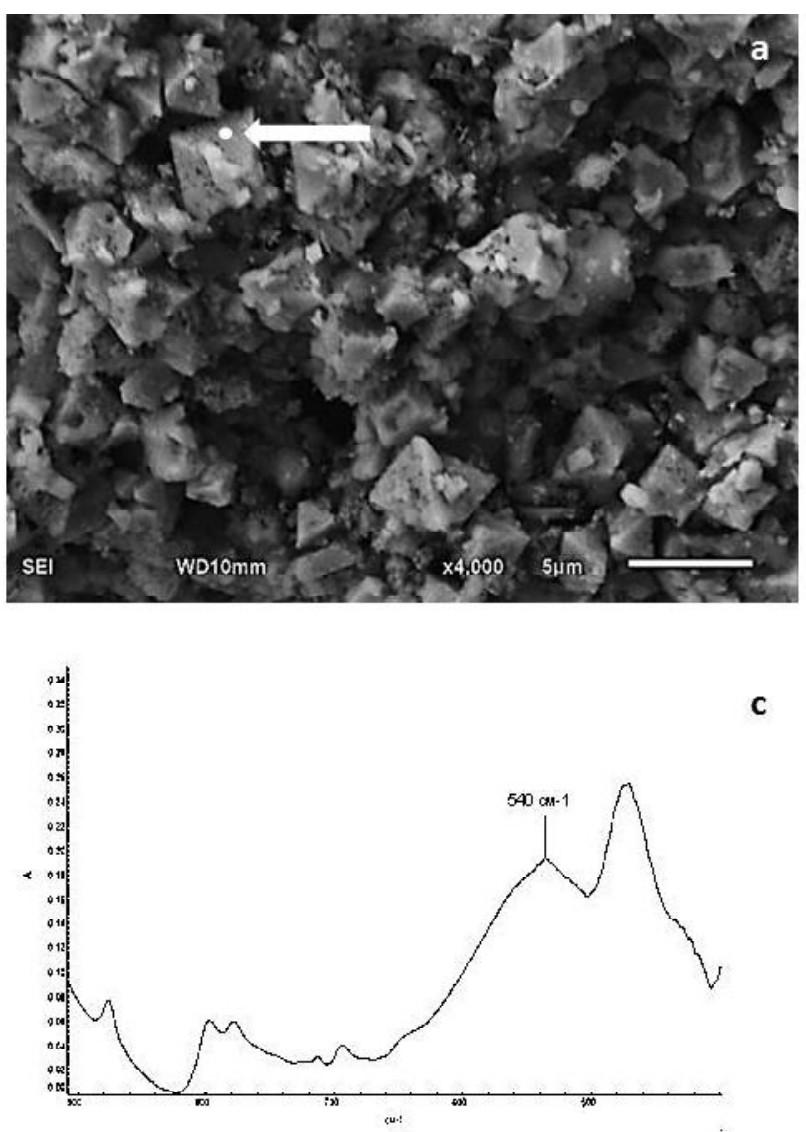

C

\begin{tabular}{l|l}
\hline Element & Weight\% \\
& \\
$\mathrm{O}$ & 31.25 \\
$\mathrm{Al}$ & 0.81 \\
$\mathrm{Si}$ & 0.74 \\
$\mathrm{Fe}$ & 67.20 \\
\hline
\end{tabular}

Рис. 2. Микроморфология кристаллов гематита из образца пигмента № 1 (a), химический состав кристаллов гематита по данным энергодисперсионного спектрометра $(b, d)$, инфракрасный спектр гематита $(c)$

Fig. 2. Micromorphology of hematite crystals from pigment sample no. 1 (a),

chemical composition of hematite crystals according to data of the energy-dispersive X-ray spectroscopy $(b, d)$, infrared spectrum of hematite $(c)$

Таблица 2

\section{Минералогический состав изученных образцов пигментов (полуколичественный)}

\begin{tabular}{|l|c|c|c|}
\hline \multicolumn{1}{|c|}{ Образец } & № 1 & № 2 & № 3 \\
\hline Гетит & + & & + \\
\hline Гематит & + & ++ & + \\
\hline Манганит & & & + \\
\hline Кварц & ++ & + & ++ \\
\hline Тридимит & & & \\
\hline Альбит & + & & + \\
\hline Микро клин & & & + \\
\hline Анортит & + & & \\
\hline Каолинит & & & + \\
\hline Иллит & & & + \\
\hline Мусковит & + & + & \\
\hline Вермикулит & + & & \\
\hline Кальцит & + & + & \\
\hline Гипс & & + & \\
\hline
\end{tabular}

В окислительных условиях и в присутствии аморфного кремнезема ферригидрит переходит в гематит. Новообразованные кристаллы гематита имеют размер около 10-40 нм (средние значения около 20 нм) [5], что значительно меньше кристаллов, обнаруженных в об- 


\section{МЕЖДИСЦИПЛИНАРНЫЕ ИССЛЕДОВАНИЯ}

разце № 1. Такой размер и правильная форма кристаллов гематита могут говорить о его эндогенном происхождении и возможной добыче из рудного месторождения.

Образец № 2 характеризуется достаточной однородностью минерального состава, и основной фазой в нем является гематит (см. табл. 2). Кроме того, в его составе присутствуют только устойчивые к температурному воздействию минералы. Исключение составляет гипс, но этот минерал мог попасть в состав пигмента из почвы.

Инфракрасный спектр данного образца характеризуется смещением полосы гематита $540 \mathrm{~cm}^{-1}$ в сторону высоких частот до $575 \mathrm{~cm}^{-1}$, что характерно для протогематита при прокаливании его до $700{ }^{\circ} \mathrm{C}$ [13, p. 398]. Исследование микроморфологии образца показало, что кристаллы железа здесь образуют плотные скопления и их размеры значи- тельно более мелкие по сравнению с кристаллами в образцах других пигментов (см. рис. 3). Отмечается «вплавление» биолитов в общую массу кристаллов железа. Наличие таких структур в образцах охр может являться признаком их термического производства. Совокупность данных признаков позволяет предположить, что гематит в образце № 2 подвергался термической обработке.

Минеральный состав образца № 3 характеризуется преобладанием совместного нахождения гетита и гематита (см. табл. 2). Причем количество первого несколько больше. Характерной чертой является наличие глинистых минералов, также манганита, который, по всей видимости, и придает пигменту более темный оттенок. Этот минерал не входит в состав плиты дольмена, на которой была найдена охра, не встречается он и в других изученных пигментах с этого сооружения. Ман-

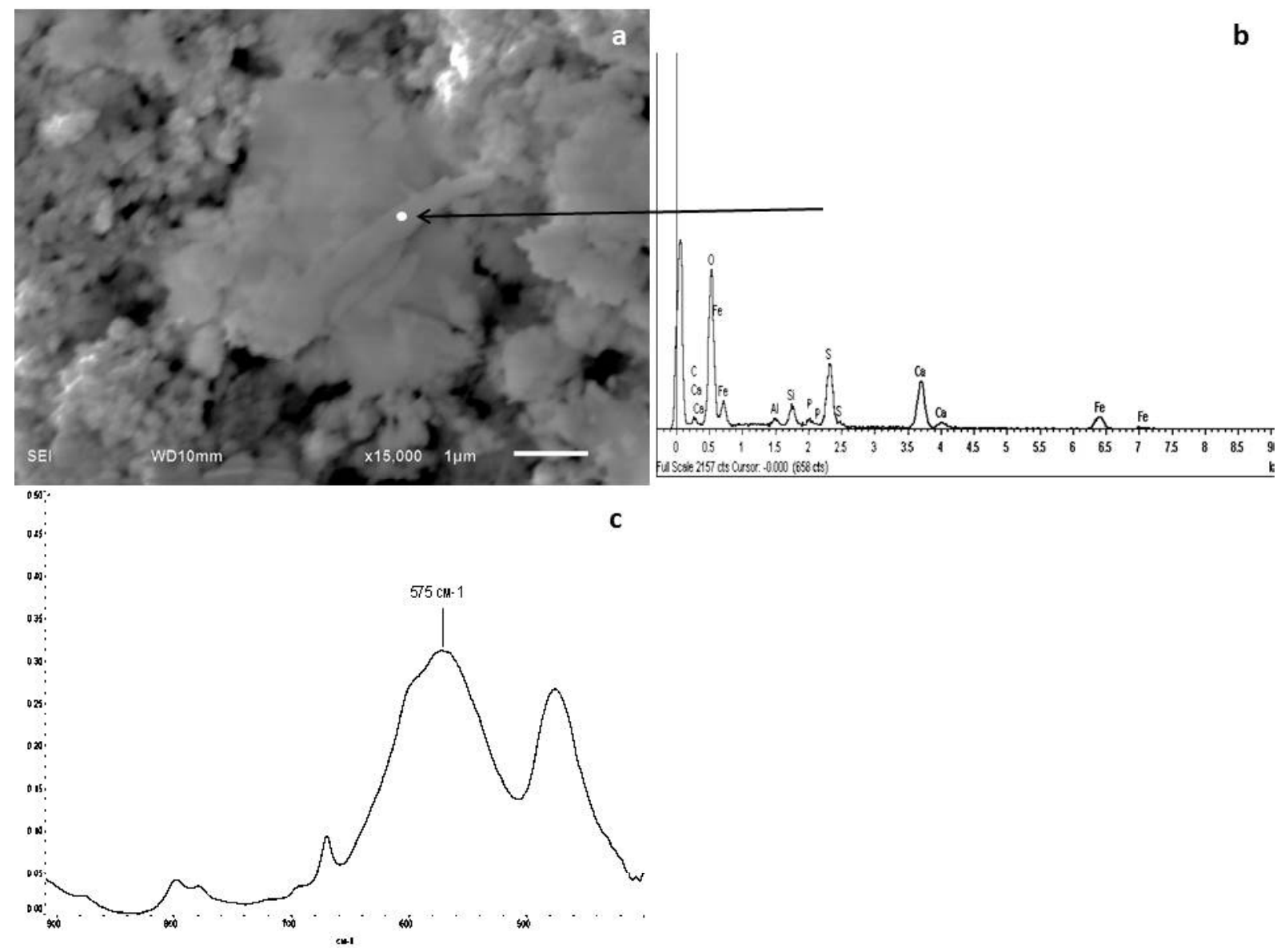

Рис. 3. Микроморфология образца пигмента № $2(a)$, химический состав биолита по данным энергодисперсионной рентгеновской спектроскопии $(b)$, инфракрасный спектр гематита $(c)$

Fig. 3. Micromorphology of the pigment sample no. $2(a)$, the chemical composition of the bioliths according to data of the energy-dispersive X-ray spectroscopy $(b)$, the infrared spectrum of hematite $(c)$ 
ганит начинает разрушаться при температуpe $300{ }^{\circ} \mathrm{C}$, гетит - при $340{ }^{\circ} \mathrm{C}$.

Наличие в образце двух неустойчивых к термической обработке минералов гетита и манганита, так же как и глинистых минералов (каолинита и иллита), а также отсутствие уплотнения кристаллов вещества и признаков вплавления биолитов (рис. 4) может свидетельствовать о том, что процесса обжига при приготовлении пигмента не происходило. Кроме того, при микроморфологическом анализе образца не обнаружено крупных кристаллов гематита, что может говорить о его осадочном происхождении или принадлежности к зоне гипергенеза.

\section{Результаты}

1. Для получения надежных доказательств термического воздействия на пигменты необходимо применять комплексный подход с использованием рентгеновской дифрактометрии, элементного анализа, инфракрасной спектроскопии и анализа микроструктуры пигмента.

2. Форма и размер кристаллов гематита в погребении у ст-цы Ладожская (образец № 1) указывают на отсутствие его термической обработки и эндогенное происхождение (возможно, из рудного месторождения).

3. В образце из погребения у ст-цы Казанская (образец № 2) выявлены признаки термической обработки минерального пигмента.
4. В образце из ст-цы Новосвободная (образец № 3) не обнаружено признаков обжига, а микроструктура пигмента указывает на осадочное происхождение минералов железа, из которых он состоит.

5. Сравнение химического состава и цветовой гаммы изученных образцов позволяет сделать вывод, что цвет пигментов не зависит от количества содержания в них железа. Наиболее значимым является наличие и соотношение гематита и гетита в пигменте, а также состав примесей других минералов в исходном продукте.

\section{ПРИМЕЧАНИЕ}

1 Работа выполнена при частичной финансовой поддержке РФФИ, гранта № 16-06-00026 А.

\section{СПИСОК ЛИТЕРАТУРЫ}

1. Балабина, В. И. Исследование охр из погребений эпохи бронзы в низовьях Дона / В. И. Балабина, Л. А. Борисенок, Л. К. Яхонтова // Советская Археология. - 1990. - № 1. - С. 154-166.

2. Водяницкий, Ю. Н. Оксиды железа и их роль в плодородии почв / Ю. Н. Водяницкий. - М. : Наука, 1989. - 160 с.

3. Горбунов, Н. И. Методы минералогического и микроморфологического изучения почв / Н. И. Горбунов. - М. : Наука, 1971. - 175 с.

4. Дольмены станицы Царской: красные пигменты как продукт производства и потребления
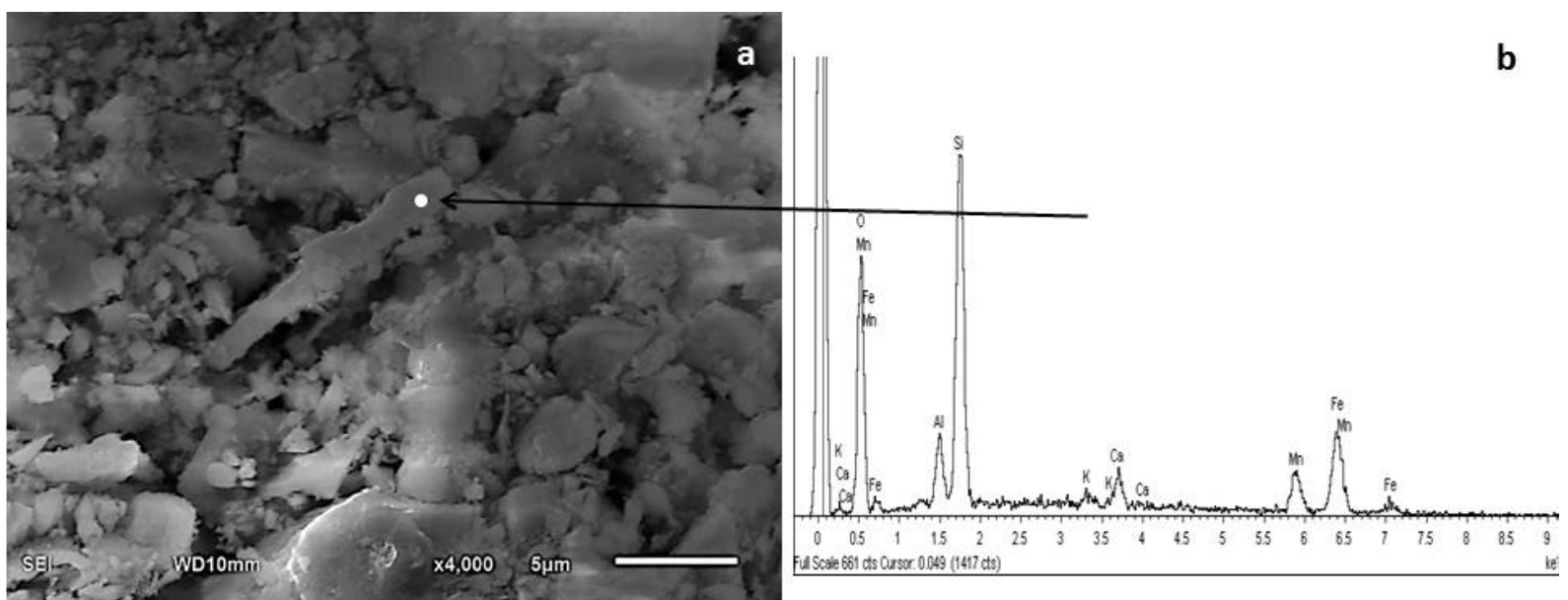

Рис. 4. Микроморфология образца пигмента № 3 (a) и химический состав биолита по данным энергодисперсионной рентгеновской спектроскопии $(b)$

Fig. 4. Micromorphology of the pigment sample no. $3(a)$ and the chemical composition of the bioliths according to data of the energy-dispersive X-ray spectroscopy $(b)$ 


\section{МЕЖДИСЦИПЛИНАРНЫЕ ИССЛЕДОВАНИЯ}

/ В. А. Трифонов, Н. И Шишлина, П. И. Калинин, А. О. Алексеев, Е. С. Богомолов // Российская археология. - 2015. - № 4. - С. 35-47.

5. Магнетизм почв / В. Ф. Бабанин, В. И. Трухин, Л. О. Карпачевский, А. В. Иванов, В. В. Морозов. - М. ; Ярославль : ЯГТУ, 1995. - 222 с.

6. Отчет Императорской археологической комиссии за 1898 год. - СПб., 1901. - 191 с.

7. Отчет Императорской археологической комиссии за 1901 год. - СПб., 1903. - 198 с.

8. Отчет Императорской археологической комиссии за 1902 год. - СПб., 1904. - 199 с.

9. Спицын, А. А. Курганы с окрашенными костяками / А. А. Спицын // Записки Русского Археологического Общества. - 1899. - Т. ХІ. - Вып. 1/2. Новая серия. - С. 53-133.

10. Blake, R. L. Refinement of the hematite structure / R. L. Blake, R. E. Hessevick// American Mineralogist. 1966. - № 51. - P. 123.

11. Schwertman, U. Encyclopedia of Soil Science / U. Schwertman. - Berlin : Springer, 2008. - Chapter IRON OXIDES. - P. 363-369.

12. Strakhov, N. M. Possibilities of formation of ferric hydroxides on the martian surface/N. M. Strakhov//Soviet astronomy. -1967. - Vol. 10, № 6. - P. 1013-1016.

13. Structure of the Metastable Modification of Iron(III) Oxide / E. B. Burgina, G. N. Kustova, S. V. Tsybulya, G. N. Kryukova, G. S. Litvak, L. A. Isupova, V.A. Sadykov// Journal of Structural Chemistry. - 2000.Vol. 41, № 3. - P. 396-402. - DOI: 10.1007/BF02741997.

\section{REFERENCES}

1. Balabina V.I., Borisenok L.A., Yakhontova L.K. Issledovanie okhr iz pogrebeniy epokhi bronzy $\mathrm{v}$ nizovyakh Dona [The Study of the Ochre from the Bronze Age Burials in the Lower Reaches of the Don]. Sovetskaya arkheologiya [Soviet Archaeology], 1990, no. 1, pp. 154-166.

2. Vodyanitskiy U.N. Oksidy zheleza i ikh rolv plodorodii poch $v$ [Iron Oxides and Their Role in Soil Fertility]. Moscow, Nauka Publ., 1989. 160 p.

3. Gorbunov N.I. Metody mineralogicheskogo i mikromorfologicheskogo izucheniya pochv [The
Methods of Mineralogical Study of Soils]. Moscow, Nauka Publ., 1971. 175 p.

4. Trifonov V.A., Shishlina N.I., Kalinin P.I., Alekseev A.O, Bogomolov E.S. Dolmeny stanitsy Tsarskoy: krasnye pigmenty kak produkt proizvodstva i potrebleniya [Dolmens of the Tsarskaya Cossack Village: Red Pigments as a Product of Manufacture and Consumption]. Rossiyskaya arkheologiya [Russian Archaeology], 2015, no. 4, pp. 35-47.

5. Babanin V. F., Trukhin V.I., Karpachevskiy L. O., Ivanov A. B., Morozov V. V. Magnetizm pochv [Soils' Magnetism]. Moscow; Yaroslavl, YaGTU Publ., 1995. $222 \mathrm{p}$.

6. Otchet Imperatorskoy arkheologicheskoy komissii za 1898 god [Report of the Imperial Archaeological Commission for 1898]. Saint Petersburg, 1901. $191 \mathrm{p}$.

7. Otchet Imperatorskoy arkheologicheskoy komissii za 1901 god [Report of the Imperial Archaeological Commission for 1901]. Saint Petersburg, 1903. $198 \mathrm{p}$.

8. Otchet Imperatorskoy arkheologicheskoy komissii za 1902 god [Report of the Imperial Archaeological Commission for 1902]. Saint Petersburg, 1904. 199 p.

9. Spitsyn A.A. Kurgany s okrashennymi kostyakami [Barrows with colored skeletons]. Zapiski Russkogo arkheologicheskogo obshchestva. Vyp. 1/ 2. Novaya seriya [Notes of Russian Archaeological Community. Iss. S. New Series]. Saint Petersburg, Tip. I.N. Skorokhodova. 1899, vol. XI, pp. 53-133.

10. Blake R. L., Hessevick R. E. Refinement of the hematite structure. American Mineralogist, 1966, no. 51, p. 123.

11. Schwertman U. Iron Oxides. Encyclopedia of Soil Science. Berlin, Springer, 2008, pp. 363-369.

12. Strakhov N.M. Possibilities of formation of ferric hydroxides on the martian surface. Soviet astronomy, 1967, vol. 10, no. 6, pp. 1013-1016.

13. Burgina E.B., Kustova G.N., Tsybulya S.V., Kryukova G. N., Litvak G. S., Isupova L. A., Sadykov V. A. Structure of the Metastable Modification of Iron(III) Oxide. Journal of Structural Chemistry, 2000, vol. 41, no. 3, pp. 396-402. DOI: 10.1007/ BF02741997. 


\section{Information about the Authors}

Pavel I. Kalinin, Candidate of Sciences (Geology and Mineralogy), Senior Researcher, Laboratory of Geochemistry and Mineralogy of Soils, Institute of Physical-Chemical and Biological Problems of Soil Science, Russian Academy of Sciences, Institutskaya St., 2, 142290 Pushchino, Russian Federation, kalinin331@rambler.ru, https://orcid.org/0000-0002-4674-7076

Viktor A. Trifonov, Candidate of Sciences (History), Senior Researcher, Department of Archaeology of Central Asia and Caucasus, Institute for the History of Material Culture, Russian Academy of Sciences, Dvortsovaya Emb., 18, 191186 Saint Petersburg, Russian Federation, viktor_trifonov@mail.ru, https://orcid.org/0000-0002-3188-9311

Natalya I. Shishlina, Doctor of Sciences (History), Head of Department of Archaeological Monuments, State Historical Museum, Red Square, 1, 125009 Moscow, Russian Federation, nshishlina@mail.ru, https:// orcid.org/0000-0001-9638-0156

Andrey O. Alekseev, Corresponding Member of Russian Academy of Sciences, Doctor of Sciences (Biology), Head of Laboratory of Geochemistry and Mineralogy of Soils, Institute of Physical-Chemical and Biological Problems of Soil Science, Russian Academy of Sciences, Institutskaya St., 2, 142290 Pushchino, Russian Federation, alekseev@issp.serpukhov.su, https://orcid.org/0000-0001-5158-4454

\section{Информация об авторах}

Павел Иванович Калинин, кандидат геолого-минералогических наук, старший научный сотрудник лаборатории геохимии и минералогии почв, Институт физико-химических и биологических проблем почвоведения РАН, ул. Институтская, 2, 142290 г. Пущино, Российская Федерация, kalinin331@rambler.ru, https://orcid.org/0000-0002-7252-2997

Виктор Анатольевич Трифонов, кандидат исторических наук, старший научный сотрудник Отдела археологии Центральной Азии и Кавказа, Институт истории материальной культуры РАН, Дворцовая наб., 18, 191186 г. Санкт-Петербург, Российская Федерация, viktor_trifonov@mail.ru, https://orcid.org/0000-0002-3188-9311

Наталья Ивановна Шишлина, доктор исторических наук, заведующая отделом археологических памятников, Государственный исторический музей, Красная площадь, 1, 125009 г. Москва, Российская Федерация, nshishlina@mail.ru, https://orcid.org/0000-0001-9638-0156

Андрей Олегович Алексеев, член-корреспондент РАН, доктор биологических наук, заведующий лабораторией геохимии и минералогии почв, Институт физико-химических и биологических проблем почвоведения РАН, ул. Институтская, 2, 142290 г. Пущино, Российская Федерация, alekseev@issp.serpukhov.su, https://orcid.org/0000-0001-5158-4454 